NBER WORKING PAPER SERIES

\title{
CHEAPER BY THE DOZEN: \\ USING SIBLING DISCOUNTS AT CATHOLIC SCHOOLS TO ESTIMATE THE PRICE ELASTICITY OF PRIVATE SCHOOL ATTENDANCE
}

\author{
Susan Dynarski \\ Jonathan Gruber \\ Danielle Li \\ Working Paper 15461 \\ http://www.nber.org/papers/w15461 \\ NATIONAL BUREAU OF ECONOMIC RESEARCH \\ 1050 Massachusetts Avenue \\ Cambridge, MA 02138 \\ October 2009
}

We are grateful to Elizabeth Kent and J.D. LaRock for collecting the tuition data. We thank Jim Davis and John Abowd for steering us through the process of gaining access to the restricted-use Census data. We have benefited from the comments of seminar participants at MIT, the NBER, and University of Michigan. The research in this paper was conducted while the authors were Special Sworn Status researchers of the U.S. Census Bureau at the Boston and Michigan Census Research Data Centers. Research results and conclusions expressed are those of the authors and do not necessarily reflect the views of the Census Bureau. This paper has been screened to insure that no confidential data are revealed. This research is supported by US Department of Education Grant Number R3O5AO8O. Dynarski is the corresponding author (dynarski@umich.edu). The views expressed herein are those of the author(s) and do not necessarily reflect the views of the National Bureau of Economic Research.

(C) 2009 by Susan Dynarski, Jonathan Gruber, and Danielle Li. All rights reserved. Short sections of text, not to exceed two paragraphs, may be quoted without explicit permission provided that full credit, including $\odot$ notice, is given to the source. 
Cheaper By the Dozen: Using Sibling Discounts at Catholic Schools to Estimate the Price Elasticity of Private School Attendance

Susan Dynarski, Jonathan Gruber, and Danielle Li

NBER Working Paper No. 15461

October 2009

JEL No. I20,I28

\begin{abstract}
The effect of vouchers on sorting between private and public schools depends upon the price elasticity of demand for private schooling. Estimating this elasticity is empirically challenging because prices and quantities are jointly determined in the market for private schooling. We exploit a unique and previously undocumented source of variation in private school tuition to estimate this key parameter. A majority of Catholic elementary schools offer discounts to families that enroll more than one child in the school in a given year. Catholic school tuition costs therefore depend upon the interaction of the number and spacing of a family's children with the pricing policies of the local school. This within-neighborhood variation in tuition prices allows us to control for unobserved determinants of demand with a set fine geographic group fixed effects while still identifying the price parameter. We analyze this variation by using data on over 3700 school tuition schedules collected from Catholic schools around the nation, matched to restricted Census data that identifies precise location that can be matched to the nearest Catholic school. We find that a standard deviation decrease in tuition prices increases the probability that a family will send its children to private school by one half percentage point, which translates into an elasticity of Catholic school attendance with respect to tuition costs of -0.19 . Our subgroup results suggest that a voucher program would disproportionately induce into private schools those who, along observable dimensions, are unlike those who currently attend private school.
\end{abstract}

Susan Dynarski

University of Michigan

Weill Hall

735 South State Street

Ann Arbor, MI 48109-3091

and NBER

dynarski@umich.edu

Jonathan Gruber

MIT Department of Economics

E52-355

50 Memorial Drive

Cambridge, MA 02142-1347

and NBER

gruberj@mit.edu
Danielle Li

Massachusetts Institute of Technology

58 Plympton St \#518

Cambridge, MA 02138

d_li@mit.edu 


\section{Introduction}

One of the most important public policy debates over the past decade has been the appropriate role of school choice in U.S. education policy. Starting with Milton Friedman (1962), proponents of school choice have advocated funding schools through a system of portable vouchers that would allow families to purchase education at the school of their choice and, thereby, create competitive pressures on public schools. The generation of such competitive pressures depends upon the willingness and ability of parents to move their children between schools, particularly from public schools to private schools. In particular, the response to a voucher program depends critically on the price elasticity of demand for private schooling.

Evidence of the responsiveness of families to private schooling prices is remarkably thin. Derek Neal (2002) notes that there is extensive research on the effect of private schools on student outcomes, but comparatively little empirical evidence of how tuition prices affect the decision to attend a private school. ${ }^{1}$ This is a challenging parameter to estimate. In fact, a regression of quantity on price is frequently used in econometrics textbooks to illustrate the challenges of estimating causal parameters with observational data. Without (quasi-) random variation in the tuition prices set by schools, a regression of quantity on price captures movement along both the supply curve and the demand curve.

We exploit a unique source of variation in tuition prices to estimate the price elasticity of demand for private schooling. The majority of Catholic elementary schools offer sibling discounts. These discounts reduce schooling costs for families that, in a given year, enroll more than one child in a single Catholic school. We have collected data on these discounts from schools representing over half of Catholic school enrollment in the US. On average, the tuition charged for the second sibling enrolled in a Catholic elementary school is 25 percent lower than tuition for the first sibling, and the tuition is 36 percent lower for the third sibling than for the first sibling. Each school establishes its own pricing schedule; about half of schools offer the discounts. Discounts vary dramatically, even within a metropolitan area. As a result of these pricing schedules, the tuition prices faced by a family are a

$1 \quad$ In order to predict how a voucher program would affect the distribution of students between public and private schools, Neal relies on theoretical predictions of Epple and Romano $(1998,2002)$. The present paper aims to provide an empirical foundation for this critical prediction. 
function of the interaction of the number and spacing of their children with the pricing policies of the local Catholic school.

To execute this strategy, we have collected a new data set of the tuition schedules offered at Catholic schools. We have collected, from 60 Catholic dioceses, information on the tuition schedules of 1760 schools, representing over one-third of all Catholic school enrollment in the U.S. We match this newly collected tuition data to restricted-use Census data that identify the block in which a household is located. This variation in tuition prices across families within a given neighborhood allows us to include in our demand equation a detailed set of block-group fixed effects to control for any unobserved determinants of demand that vary across space. Since the discounts vary considerably across schools, we are also able to control flexibly for the number, spacing and ages of children in each family, thereby absorbing any nationwide, underlying relationship between family composition and private school attendance.

We find that a standard deviation decrease in tuition prices increases the probability that a family will send its children to private school by over two thirds of a percentage point. This translates into an elasticity of Catholic school attendance with respect to tuition costs of -0.19 . This average effect masks substantial heterogeneity in the response to price, with lower income families and those with less educated parents being more price sensitive. These results strongly reject the assumption made in previous studies (e.g., Figlio and Stone, 2001; Lankford and Wyckoff, 2001) that the students that vouchers would induce into private school would look demographically similar to current private school students.

Our paper proceeds as follows. In Section II, we present a simple theoretical motivation for our topic, drawing on the seminal model of Peltzman (1973) to highlight the centrality of the price elasticity of demand in the evaluation of voucher programs. In Section III, we discuss empirical challenges in the estimation of the price elasticity of demand for private schooling and critically review the existing literature on this topic. Section IV lays out our identification strategy and discusses the characteristics of the tuition and census data. Our basic results and sensitivity tests are presented in Section V, while Section VI presents evidence on the heterogeneity of price elasticity and Section VII concludes. 


\section{Theoretical Motivation}

The starting point for our analysis is the seminal school choice model of Peltzman (1973). Figure 1A illustrates a family's choice between education and all other goods in the absence of the public provision of education. The family has a total budget of $\$ Q_{0}$; the price of private education is $p$ (the slope of the budget line), and the price of other goods is normalized to 1 . There is a smooth tradeoff between the consumption of education and of other goods. The optimal choice is $E_{1}$, the point at which (constrained by budget $\$ \mathrm{Q}_{0}$ ) a consumer's marginal rate of substitution between other goods and education is $p$.

Now introduce the public provision of education. The public sector provides education of amount $\mathrm{E}_{\mathrm{F}}$. Consumers can spend $\$ \mathrm{Q}_{0}$ on other goods and still consume $\mathrm{E}_{\mathrm{F}}$. Parents who wish to purchase a higher quantity must send their children to private school, thereby forgoing their entitlement to free public education (there is no "topping off” allowed). Consider the schooling choice of a family with an indifference curve tangent to the budget constraint at $X_{1}$. This family could choose private schooling, and obtain more education at $E_{1}>E_{F}$ but consumption would fall. Given this family's marginal rate of substitution between other goods and education, it would prefer the free, public education.

Next we add vouchers to the model. The private enrollment response to a voucher depends on the size of the voucher and the preferences of consumers. A larger voucher (Figure 1C) will move more families into private school than a smaller voucher (Figure 1D). Were all families identical, all families would choose the same schooling option (e.g. private school in Figure 1C, public in Figure 1D). But if preferences are heterogeneous, a large voucher (Figure 1E) will move into private school some families unmoved by a small voucher (Figure 1F). Heterogeneity in underlying tastes can lead to a smooth aggregate relationship between voucher levels and choice of private schooling.

Thus, we can derive a demand curve for the relationship between the cost of going to private school rather than public school and the share of families choosing private rather than public school. This demand curve will depend on the relative densities of different types in the population. In principle, the demand elasticity could be very non-linear, because different price changes could hit individuals with very different marginal rates of substitution across public and private schooling. 


\section{Empirical Issues in Estimating the Price Elasticity of Private Schooling}

In principle, estimating the price elasticity of demand for private schooling is straightforward: individual school enrollment $(y)$ is regressed on the price of nearby private schools. In Equation (1), a binary measure of the private school attendance of child $i$ living in family $j$ living in area $b$ is regressed on the price of private schools in geographic area $b$ :

(1) $y_{i j b}=\beta_{0}+\beta_{1}$ price $_{b}+\varepsilon_{i j b}$

Equation (1) estimates the association between a dollar increase in private school tuition and the

probability that individual $i$ attends private school. We would like to interpret $\hat{\beta}_{1}$ as the causal impact of price on private school attendance. However, the price faced by individual $i$ is likely a function of omitted variables correlated with the demand for private schooling. For example, in high-income areas both price and the attendance rate will be above average if private school is a normal good. Controlling for income, along with other covariates, is one way to deal with this problem:

(2) $y_{i j b}=\beta_{0}+\beta_{1}$ price $_{b}+\beta_{2} X_{j}+\beta_{3} X_{b}+\varepsilon_{i j b}$

Control variables typically included in this type of regression include characteristics of the parents in family $j$ (e.g., marital status, race, education, age) and characteristics of the geographic area $b$ (e.g., poverty rate, population density, local public school characteristics). The central weakness in this approach is that cross-sectional variation in equilibrium tuition prices reflects not only variation in the supply of schools (useful for the purposes of identifying a demand elasticity) but also in the demand for schools (which will bias estimates of demand elasticities).

A number of studies have taken the empirical approach of Equation (2). Keeler and Kriesel (1994) estimate the relationship between tuition prices and the share of children in the district attending private schools in 105 school districts in Georgia; their cross-sectional estimates suggest an elasticity of 1.04. Buddin, Cordes and Kirby (1998) estimate the relationship between tuition prices and private school attendance in California and conclude that "[T] he propensity of families to choose private schools is insensitive to out-of-pocket tuition costs, which implies that providing school vouchers would encourage few families to shift from public to private schools.” Erekson (1982) examines the relationship between private school attendance and Catholic school prices in New York State and finds that Catholic school 
attendance increases with tuition prices. Lankford and Wyckoff (1992), using similar data, find a negative relationship between price and attendance. Chiswick and Koutromanes (1996) correlate private school attendance with variation in private school tuition at the state level. They estimate that an increase in tuition prices from $\$ 1,000$ to $\$ 4,000$ decreases the probability of choosing a private school from 23 percent to 17 percent, calculating an overall price elasticity of -0.48 .

Long and Toma (1988) model the determinants of private school attendance using 1970 and 1980 Census data. They are primarily interested in the relationship between race, income and private school attendance, but also include a "tuition" variable in their models. Since they do not have direct measures of private school tuition they proxy for tuition costs with the state-level average of private school salary costs per employee. They estimate the relationship between this tuition proxy and private school attendance for several different years and for different levels of schooling, obtaining estimates that range from statistically insignificant and negative to statistically significant and positive.

The mixed and sometimes perverse results in this literature may reflect a common flaw: a lack of exogenous variation in private school prices. The prices of private school are equilibrium outcomes, determined by both the supply of and demand for private schooling. The price coefficient in Equation (2) is identified only under the very strong assumption that observable characteristics fully capture variation in the demand for private schooling. But some determinants of demand are unobservable in typical datasets and so cannot be included in this vector of controls. In areas with a high taste for private school, we will observe both high enrollment rates and high tuitions, which both reflect the higher demand for private school. This will positively bias our price coefficient. Alternatively, in the case of Catholic schools, the bias could be negative: the degree of commitment to the Catholic faith is likely positively correlated with demand for Catholic schooling and negatively correlated with price, since committed parishioners will subsidize the local school's tuition costs with their donations. This would cause us to overestimate the price elasticity of demand for private school attendance.

Ideally, we would randomly assign private school vouchers of varying values, observe responses, and thereby estimate the price elasticity of demand for private schooling. In fact, the randomized assignment of vouchers has occurred in Milwaukee, New York, Dayton, and Washington, DC. Analysts of these experiments are primarily concerned with estimating the impact of private school attendance on 
student performance (Rouse, 1998; Witte and Thorn, 1996; Mayer et al., 2002). They typically use instrumental variables regression in their empirical analysis, with the reaction of families’ schooling choices to the offer of a voucher forming the first-stage and the effect of private school attendance on educational outcomes forming the second stage.

These studies do not calculate the demand elasticities implied by the first stage. This is understandable, since their central identification concern is the exogeneity of the relationship between the voucher offer and schooling choices, not the size of the relationship. The price changes are large and discrete, and so are the changes in attendance rates, so the calculated elasticities are very sensitive to whether the baseline attendance rate used in the calculation is that of the treatment or the control group. If we choose the control group as the "base," the elasticities are -6 in Dayton, -9 in Washington and -23 in New York City, while if the treated group is the base case then the elasticities are -1.4, -1.3 and -1.4, respectively. ${ }^{2}$ Either approach suggests that families are highly elastic in their response to tuition price. However, a plausible explanation for these magnitudes is that the studied population is nonrepresentative: only those who most desire to attend private school, and whose enrollment hinges on the provision of a subsidy, may be willing to submit to the time demands of a randomized trial over several years (e.g., meetings at nights and on weekend, standardized testing, lengthy surveys that ask for personal information). The bottom line is that the voucher trials produce internally valid estimates of the price elasticity of private school attendance but they are of limited external validity.

A related body of research seeks to predict who will be shifted into private schools by a voucher by describing the population of students who currently attend private schools. These studies assume that the type of student that currently attends private school is the type of student that will be induced into private school by a voucher. This is a strong assumption, one that our empirical research can test directly. Figlio and Stone (2001) use NELS data to show that private schools are disproportionately attended by

$2 \quad$ Consider Dayton, where the was voucher capped at 60 percent of tuition, private school attendance rate of the treatment group was 78 percent and that of the control group 18 percent (Howell et al, 2002). The implied elasticity is $-1.3[=((78-18) / 78) /-0.6]$ when we use the treatment group as the base and $-6[=((78-18) / 18) /-0.6]$ when we use the control group as the base. No voucher program has randomly assigned vouchers of differing values. Such an experimental design would allow for the direct estimation of price elasticities, rather than the averages just calculated. An advantage of our research design is that it provides continuous variation in price, rather than the discrete, large shifts that characterize the voucher studies. 
white students whose parents are of high socioeconomic status. Lankford and Wyckoff (2001) examine the relationship between students and family characteristics and school choice, again using NELS. They find that higher income families are more likely to send their children to private schools.

\section{Identification Strategy}

The key threat to the internal validity of the observational studies we have discussed is that tuition prices charged by private schools are plausibly driven by local demand for private schooling. We address this threat by controlling for an extremely fine set of neighborhood fixed effects:

(3) $y_{j b}=\beta_{0}+\beta_{1}$ price $_{j b}+\delta_{b}+\varepsilon_{j b}$

In this equation, $y_{j b}$ indicates the private school choice of family $j$ who lives in neighborhood $b$. Our key explanatory variable is price $_{j b}$ the tuition charged by the private school located nearest the neighborhood.

$\delta_{b}$ denotes a set of neighborhood fixed effects. ${ }^{3}$ The neighborhood fixed effects absorb any variation between neighborhoods in the unobserved and unobserved demand for private schooling. For example, they control for variation across neighborhoods in income, parental education and the taste for private schooling.

Critically, this empirical strategy requires that private school prices vary within a neighborhood. In the absence of price variation within neighborhoods, the price coefficient Equation in (3) is not identified. As we next describe, we have identified variation in tuition prices that occurs within neighborhoods. After describing those data, we return to defining out our empirical strategy, showing how we will use these data to identify the price elasticity of demand for private schooling.

\section{Sibling Discounts at Catholic Schools}

Table 1 shows the tuition prices charged by two private, Catholic schools in Columbus, Ohio. These elementary schools are quite similar in size and both enroll children in kindergarten through eighth grade. Families enrolling one child in these two schools face similar costs: St. Catherine’s charges \$1,125 and Blessed Sacrament $\$ 1,200$. But families seeking to enroll two children face very different costs:

3 We will make more concrete our definition of neighborhood, and which school serves it, later in the paper. 
Blessed Sacrament charges $\$ 1,200$ for the second child but St. Catherine’s charges only $\$ 325$. The costs diverge still further if a family has three children it wishes to enroll: St. Catherine's charges no tuition for the third child while Blessed Sacrament continues to charge its flat rate of $\$ 1,200$. These sibling discounts are school-specific, applying only if siblings are enrolled in the same Catholic school in the same year.

We knew of these discounts because the first author attended a Catholic elementary school that discounted tuition for siblings. Intrigued by the possibility of exploiting this source of variation in tuition prices, we searched for a dataset or publication that documented them in detail but found no such resource. We did learn from the National Catholic Education Association (NCEA) that dioceses, the subnational administrative unit of the Catholic Church in the US, do collect such data from the schools in their region. We contacted a few large dioceses and (after hand-entering the data) confirmed that the discounts were widespread and variable, both across and within dioceses.

We therefore broadened our data collection efforts. We contact all 168 dioceses by mail, phone, and email (see Data Appendix for details). After repeated contacts, 136 dioceses representing 90 percent of Catholic school enrollment in the US responded. Sixty dioceses agreed to participate and sent data on 1,760 schools representing 37 percent of national Catholic school enrollment. An additional 31 dioceses (24 percent of national enrollment) agreed to participate but despite repeated confirmation of their intent did not send data. The 45 dioceses that declined to participate (29 percent of Catholic school enrollment) overwhelmingly cited lack of data or staffing constraints as the reason.

After entering and examining the data, we quickly determined our analysis would focus on elementary schools. Multiple siblings can spend more time together in an elementary school (spanning eight grades) than in a high school (spanning four grades) or a middle school (spanning three to four grades). Perhaps for this reason, sibling discounts are more prevalent at elementary schools than at high schools. ${ }^{4}$

Our sample of elementary schools quite closely resembles the universe of Catholic schools. Figure 2 shows the distribution of Catholic dioceses across the United States. Darkly-shaded circles

\footnotetext{
$4 \quad$ In particular, we focus on schools that span (at least) grades one through eight, the most common structure
} for Catholic elementary schools. 
depict Catholic school enrollment levels in the dioceses for which we have data. ${ }^{5}$ Our sample tilts toward large dioceses, both because we pursued their participation most aggressively and because the smaller dioceses frequently did not have the personnel and record keeping to allow them to respond to our data request. $^{6}$ Twenty-nine percent of all Catholic schools, and 30 percent of our sample schools, are located in the Northeast. Sixteen percent of all Catholic schools, and 19 percent of our sample schools, are in the South. Forty-four percent of all Catholic schools, and 37 percent of our sample, are in the Midwest. The average Catholic elementary school enrolls 286 students in grades kindergarten through eight, while our sample schools average 296 students.

Table 2 shows tuition data (weighted by school enrollment) for elementary schools in our sample for the 1999-2000 academic year. For the first sibling, the mean tuition charged is $\$ 1,975$; in all Catholic schools, the average tuition price is $\$ 2,178$ (figure is for $2000-2001$ and is taken from Kealey, 2002). Sibling discounts are widespread and variable. For the second sibling the mean tuition charged is $\$ 1,473$ and for the third and fourth siblings the means are $\$ 1,258$ and $\$ 1,103$, respectively. Tuition rates for higher-order siblings are more variable than those for the first: the standard deviation in tuition is $\$ 700$ for the first sibling but $\$ 743, \$ 1,258$ and $\$ 899$ for the second, third and fourth siblings, respectively. Fiftytwo percent of schools offer a discount for the second child, and 69 percent offer them for the third and fourth child (Table 3). Thirty-five percent of schools offer a discount of more than 25 percent for the second sibling, while 14 percent more than halve tuition for the second child. For third children the discounts are steeper, with tuition cut by more than half by 40 percent of schools. A quarter of schools discount tuition for the third sibling by more than 75 percent.

This table confirms that the sibling discounts are widespread and variable. ${ }^{7}$ Both statistical properties are critical for our identification strategy. Were sibling discounts rare, we would be unlikely to pick up their effects in the household survey data that we use to measure private school attendance. Were

5 Data from our sample and National Catholic Education Association website.

$6 \quad$ In several cases research assistants traveled to a diocese to enter data from paper records into a laptop. This was worthwhile only for large dioceses.

$7 \quad$ Most of this variation occurs within dioceses. A regression of tuition charged for the first child against a set of diocesan fixed effects yield an $\mathrm{R}^{2}$ of 0.35 , indicating that just 35 percent of the variation in tuition prices is explained in differences across dioceses in their average tuition rates. Sixty-five percent of the variation is therefore within dioceses, indicating that the schools have substantial autonomy in setting their prices. 
sibling discounts uniform, we would have difficulty disentangling their effect on private school attendance from any (perhaps nonlinear) relationship between family size and private school attendance. The spatial variation in sibling discounts will allow us to control flexibly for family structure while still identifying the relationship between price and private school attendance.

\section{Exogeneity of Multiple-Child Discounts: Qualitative Interviews}

The typical Catholic elementary school is affiliated with a local parish that subsidizes the school's operation. Parishes that subsidize their schools more heavily charge lower tuition prices. Until the mid1960s, these subsidies were close to 100 percent and the typical Catholic elementary school charged no tuition. At of 2001, parish subsidies covered just 24 percent of per-pupil expenditures for the 85 percent of schools that receive them (Kealey, 2002). Parishioners that heavily subsidize schools may be parishioners that especially desire Catholic schooling. It is exactly this endogenous price-setting that motivates our search for alternative identification strategies for identifying the price elasticity of demand for Catholic schools.

In interviews, we asked Catholic school principals how they set prices. They typically replied that they assess their costs and parish subsidy and then choose a (first-child) tuition price that will allow them to break even. Administrators never volunteered how they set sibling discounts. In response to our probes about sibling discounts, the rationale most frequently offered was that schools hope to be affordable to large families. By offering a "family rate,” a school might convince a household to send all of its children to that school. ${ }^{8}$ Several respondents volunteered there were relatively few sibling pairs or triplets in their school, so that even large discounts did not have much impact on overall revenue. In summary, it appears that the setting of first-child price is treated as a financial decision while prices for subsequent siblings are perceived as a service to local families.

\footnotetext{
$8 \quad$ Personal communications with Sister Mary Taymans of the National Catholic Educational Association,
} September 11, 2002 and Sister Judy Cauley of Archdiocese of Chicago, October 7, 2002. 


\section{Estimating Equation}

We can now describe how we will use sibling discounts in our estimation strategy. Consider families of varying sizes that live near either St. Catherine’s or Blessed Sacrament. Families enrolling one child in private school face similar tuition costs in these two neighborhoods (Table 4, \$1,125 versus $\$ 1,200)$. By contrast, families enrolling two children face very different costs $(\$ 1,450$ near St. Catherine’s and \$2,400 near Blessed Sacrament). The difference in costs between families near Blessed Sacrament and St. Catherine’s is $\$ 75$ for families enrolling one child and $\$ 950$ for families enrolling two children. Another way to look at the data in this table is that the difference in costs between families enrolling one vs. two children is \$1,200 in the neighborhood near Blessed Sacrament and \$325 near St. Catherine’s. The difference-in-difference of total tuition costs is $\$ 875$.This difference-in-difference in tuition costs forms our identifying source of variation in price.

In practice, we execute this strategy by controlling for neighborhood fixed effects and family composition fixed effects:

(4) $y_{j n b}=\beta_{0}+\beta_{1}$ price $_{n b}+\delta_{n}+\delta_{b}+\varepsilon_{j n b}$

In this equation, $y_{j n b}$ indicates the private school choice of family $j$, with composition $n$, that lives in neighborhood $b . \delta_{b}$ indicates a set of neighborhood fixed effects. We experiment with a variety of neighborhood definitions, ranging from the census tract to the census block. We ultimately settle on census block groups as our definition of a neighborhood. We describe census block groups in the next section. With the block-group fixed effects, we non-parametrically control for any unobserved differences in the demand for private education across block groups, such as the poverty rate, crime rate and population density. If schools respond to local preferences in choosing the level of their prices, then our fixed effects strategy will eliminate bias in the estimated demand elasticity.

In order for our price coefficient to be identified from the interaction of family composition and local tuition schedules, we must include flexible controls for the main effect of family composition. The discounts a family can obtain are a function of the number of children that are simultaneously of elementary-school age. A family with two children spaced eight years apart would qualify for no discount, since the children would never be in elementary school at the same time. A family with two 
children spaced two years apart would get the second child discount for the six years that the siblings' elementary school attendance overlapped. As this example makes clear, the spacing of children, as well as their number, affects the size of the family's tuition discount.

In Equation (4), $\delta_{n}$ denotes a vector of dummy variables measuring the age, number and spacing of children in a family. The dummies are constructed as follows. We calculate the age span between each adjacent sibling. For example, in a family with children of ages 3, 6 and ten, the age spans are three and four years. We then define a set of dummies that define the number of age spans of a given width in each family, and include these in the regression. ${ }^{9}$ We also include a set of eighteen age dummies that indicate the presence of children age 0 , of age 1 ...of age 18 in the household. These variables for the number and spacing of children will eliminate from the identifying variation in price the average, nationwide sibling tuition discounts. They also control for any nationwide correlation between family composition and private school attendance.

Our key explanatory variable of interest is price $_{n b}$, the total cost to a family of composition $n$ in neighborhood $b$ of sending all of its children to the nearest Catholic elementary school. This price is a function of the number and spacing of children in a family as well as the neighborhood in which the family resides. Our key outcome of interest is an indicator for whether all of the elementary-school-age children in family $j$ are enrolled in private school. We have chosen to define cost, and private school attendance, at the level of the family for two reasons. First, the schools define prices at the level of the family, rather than the individual child. Second, the data indicate that families make schooling choices at the level of the family, rather than the individual child: the overwhelmingly majority of families send either all or none of their children to private school. In the 2000 Census, among families with children of elementary school age that send any child to private school, 86 percent send all of their children to private school.

The identifying variation in schooling costs in Equation (4) has an intuitive interpretation: the equation is identified by within-neighborhood differences in the total cost of sending a family's children

\footnotetext{
9 There are 27 spacing dummies in the equations, indicating up to three occurrences of nine different age spans $(0$ to $8+)$.
} 
to the local Catholic school. Differences in total costs have a natural economic interpretation as marginal costs. The thought experiment is that (within a neighborhood) families are randomly assigned a sibling age structure, which generates variation in the total cost of sending a family's children to private school. In this thought experiment, the "marginal cost" of private schooling within a neighborhood is the cost of being assigned one sibling structure vs. another sibling structure. And since our identification comes from the interaction of family structure with tuition schedules, an equivalent thought experiment is that families with a given sibling structure are randomly assigned a sibling discount schedule. In this thought experiment, the "marginal cost" of private schooling varies across neighborhoods, and is the cost of being assigned one tuition schedule vs. another.

\section{Data on Private School Attendance: Restricted Census of Population and Housing}

Our estimation strategy requires data on children's private school attendance, as well fine geographic identifiers that allow us to link a household to the nearest private school. The Public Use Microdata Sample (PUMS) files of the 2000 Census of Population and Housing collects data on school enrollment for all household members who are age three and above. These enrollment variables capture whether i) an individual has attended school in the past two months and ii) whether that school is public or private. In Census 2000, 7.8 percent of families have all of their elementary-school age children enrolled in private school.

We conduct our analyses at the level of the Census sub-family. We construct measures of the number and ages of the children in each subfamily (hereafter referred to as a family), as well as the education, race and ethnicity of the mother and father, if present. Our analytic sample is restricted to families that contain no more than six children below age 19 and no more than three children between the ages of six and thirteen. This restriction excludes only two percent of families with any children between age six and thirteen. ${ }^{10}$

For reasons of confidentiality, fine geographic identifiers are not contained in the public-use versions of the Census. We analyze restricted-use versions of the PUMS that contain geographic 
identifiers at the level of the block. A census block is the finest geographic unit used by the Census Bureau and is its closest approximation to a neighborhood. There are about 8 million blocks in the US, ranging in population from zero to a few hundred (three million blocks are empty). Using block identifiers, we matched each family to its closest Catholic elementary school. Distance was calculated using mapping software, as the crow flies, from the population-weighted centroid of the block to each school's exact address. ${ }^{11}$ If the closest Catholic elementary school to a block was not in our analytic tuition sample, we discarded the block. A Catholic elementary school would not be in our sample for one of three reasons: the block is located in a diocese that did not give us data, the school is not administered through the Catholic diocese, or the school has a non-traditional grade structure (e.g., grades K through 5, grades 6 through 9). ${ }^{12}$ More details of the mapping and matching process are in the Data Appendix.

In our preferred specification, we control for block-group fixed effects. There are 213,607 block groups in the continental United States. A block group is a subdivision of a Census tract. Block groups typically contain 1,500 people, with a Census-defined minimum of 600 and maximum of 3,000. The typical person in the US lives in a county that contains over 700 block groups. ${ }^{13}$ Block groups are intended to be spatially-coherent units, whose boundaries consist of "visible and identifiable features, such as roads, rivers, canals, railroads, and above-ground high-tension power lines.”14

In the 1-in-6 sample of the PUMS, sub-families that meet our sample restrictions concerning the ages and number of children reside in 1,736,984 blocks that are contained in 206,703 block groups (Table 5). These 2,969,515 families include 4,235,364 children of elementary school age. About sixteen percent of these families $(463,505)$ live within ten miles of a Catholic elementary school for which we have tuition data for the years 1999, 2000 or 2001. These 463,505 families form our analytic sample.

11 The Census Bureau maintains a dataset of the latitude and longitude of each block centroid. We calculated the latitude and longitude (of the physical location) of each Catholic school using mapping software.

12 For the dioceses that sent us data, we very rarely lack tuition data for any of the schools in its catchment area.

$13 \quad$ This is the (population-weighted) average number of block groups in a county in 2000.

14 This paragraph's description of Census geographic areas is taken from US Bureau of the Census, "Census 2000 Statistical Areas Boundary Criteria," http://www.census.gov/geo/www/psapage.html\#BG, accessed January 26, 2007. 
As can be seen in Table 5, our analytic sample (Column 2) is fairly similar to the broader sample of block groups contains children of elementary school age. Unsurprisingly, private school attendance is higher in our sample (13.4 percent) than in the full sample (7.8 percent). Family size and parental race and education are similar in our analytic sample and the full Census sample of households with children between six and thirteen. Mean income is slightly higher in our analytic sample, likely reflecting the fact that our sample tilts toward urban areas and the Northeast, and away from suburbs and the South. This reflects the spatial concentration of Catholic schools.

\section{Measurement Error in Catholic School Attendance}

The census school enrollment variable does not specify whether that private school is Catholic; that question was last fielded in the 1980 Census of Population and Housing. ${ }^{15}$ How does this affect the interpretation of the price coefficients in our estimating equations? It is helpful to write private school attendance as the sum of Catholic school attendance and non-Catholic private school attendance:

$$
y=y^{\text {cath }}+y^{\text {non-cath }}
$$

Subscripts are suppressed to simplify exposition. This identity holds for families as well as in the aggregate. Plugging this identity into our key estimating equation and rearranging terms yields:

$$
\begin{aligned}
y^{\text {cath }}+y^{\text {non-cath }} & =\beta_{0}+\beta_{1} \text { price }+\varepsilon \\
y^{\text {cath }} & =\beta_{0}+\beta_{1} \text { price }+\left(\varepsilon-y^{\text {non-cath }}\right)
\end{aligned}
$$

We see that $y^{\text {non-cath }}$ is contained in the error term. If $y^{\text {non-cath }}$ is uncorrelated with price (conditional on neighborhood and family structure fixed effects) then mis-measurement in Catholic school attendance will not bias $\hat{\beta}_{1}$ and $\hat{\beta}_{1}$ is an unbiased estimate of the relationship between Catholic school prices and Catholic school attendance. This condition holds if non-Catholic schools do not offer sibling discounts, or if they offer discounts that are uncorrelated with those offered by Catholic schools. This condition also holds if non-Catholic private schools offer sibling discounts that are uniform at the national or regional

15 From the US Department of Education's Private School Survey, we do know that about half of private school attendance is in Catholic schools 
level (e.g., if the schools use the need-based financial aid formula promulgated by the Private School Scholarship Service, which incorporates a discount for larger families). Any such uniform discounts would be absorbed by our family composition fixed effects. At the opposite extreme, if non-Catholic schools offer sibling discounts identical to those offered by nearby Catholic schools, then ${ }^{\hat{\beta}_{1}}$ is an unbiased estimate of the relationship between private school prices and private school attendance, since Catholic school prices act as a perfect proxy for the tuition charged by non-Catholic private schools.

Our results suggest that the results are driven by Catholic school attendance and Catholic school prices. As we show later in the paper, the price effects are much larger among those who (based on ethnicity) are most likely to be Catholic.

\section{Results}

The baseline results are in Table 6. We start with a bivariate regression that includes on the righthand side only the family cost variable. We have multiplied the price coefficient by 100 to allow for ease of interpretation. The coefficient of -0.072 in Column (1) indicates that an increase in tuition cost of $\$ 1000$ is associated with about a tenth of a percentage point decrease in the probability of private school attendance. This coefficient is neither substantively not statistically different from zero. The equation has very little explanatory power, with a $\mathrm{R}^{2}$ of essentially zero.

This specification does not control in any way for family composition. Families with more children face higher total costs, and they may be more (less) likely to send their children to Catholic school. This would tend to produce a positive (negative) bias on the estimated coefficient. We therefore add to this bivariate regression variables (described in the previous section) that capture the ages, number and spacing of a family's children. These variables net out differences in price and private school attendance across children of different ages and families of different compositions. The coefficient of 0.454 in Column (2) indicates that, conditional on family composition, an increase in a family's tuition costs of $\$ 1000$ is associated with a 0.454 percentage point increase in the probability of the family sending all of its children to private school. The coefficient is highly significant, with a standard error of 0.08 percentage points. 
We next add to the specification plausible, observable determinants of demand: income, parents' education, ethnicity, race and parents' marital status. ${ }^{16}$ This set of covariates has some explanatory power: the $\mathrm{R}^{2}$ rises from to .05 when they are added to the regression. With the addition of these covariates the price coefficient is once again small, negative and insignificant: -0.049 with a standard error of 0.075 . This is small both statistically and substantively.

The price coefficient in these specifications is identified, in part, by variation across neighborhoods in the price of the nearest school. The zero-to-positive price coefficient likely reflects the bias predicted by a simple model of supply and demand: across neighborhoods, equilibrium levels of tuition prices and enrollment are determined both by local demand shocks, which move us along a positively-sloped supply curve, and local supply shocks, which move us along a negatively-sloped demand curve.

Geographic fixed effects allow us to control for any unobserved (and observed) determinants of demand that vary across neighborhoods. If families with similar tastes for private schooling live near each other, these fixed effects will have substantial explanatory power in our regressions. Note that our use of neighborhood fixed effects is feasible only because multiple-child discounts create variation in tuition costs within neighborhoods. The use of such fixed effects has not been possible in previous research, in which tuition costs have varied only across state or school district.

We start with a set of tract fixed effects; there are 16,609 tracts in our data. Since tract population varies from 1,500 to 8,000, this is a very loose definition of a neighborhood. But even this crude measure of geography explains more than twice as much of the variation in private schooling as observable characteristics: the $\mathrm{R}^{2}$ in a regression that includes tract effects but no demographics is 0.133 (Column 4), while that for the regression including demographics but no tract effects is 0.05 (Column 3). More importantly, the tuition coefficient becomes substantially more negative and is now highly significant (0.235, with a standard error of 0.104$)$. With the addition of covariates to this tract-effects specification, the coefficient is increases in magnitude (to -0.295) and is slightly more precise (standard error of 0.100).

16 Demographics consist of dummies for: mother's and father's education (less than high school, high school, some college, college grad); presence of mother and father; mother's and father's marital status; mother's and father's race and ethnicity; and family income ( $\$ 10 \mathrm{~K}$ brackets, with $\$ 200 \mathrm{~K}+$ a single bracket). 
This increase indicates that, even within a tract, observable family attributes are correlated with both price and school attendance.

Our data allow us to include block-group fixed effects, an even finer level of geography than tract. The typical census tract contains three census block groups; there are 42,226 block groups in our sample. The $\mathrm{R}^{2}$ in a regression that includes block-group effects but not demographics is 0.207 (Column 6), as compared to 0.133 for the tract-effects specification. The magnitude of the price coefficient increases to -0.356 when block-group fixed effects are included. This coefficient indicates that a $\$ 1,000$ increase in a family's tuition costs decreases the probability that its children attend private school by 0.36 percentage points. The coefficient is precisely estimated, with a standard error of 0.12 percentage points. Once block group fixed effects are included, the cost coefficient is insensitive to the inclusion of demographic variables: the coefficient is -0.38 with their inclusion (Column 7) and -0.36 when they are excluded (Column 6).

\section{Are Families Myopic or Forward-Looking in Their Schooling Decisions?}

We next explore alternative specifications of the price variable. We have so far assumed that families are essentially myopic, considering only current tuition costs when deciding whether to enroll their children in private school. These present costs incorporate sibling discounts for children that are currently of elementary school age, but they ignore any discounts that are produced by the private school attendance of siblings who are currently older or younger than elementary school age (that is, under six or over thirteen). A forward-looking family would consider not only today's tuition costs, but the lifetime costs of private school, which would incorporate discounts generated by all siblings in the family. In this section we show results based on these two models of family decision-making and statistically test which model better fits the data.

Consider a family with $m$ children of which $n_{t}$ are of elementary school age at time $t .{ }^{17}$ For example, assume a family that, on Census day, has three children aged, 3, 6, and 10. Their closest

\footnotetext{
17 Census measures the number of children in a family with error, since the youngest may not yet be born and the oldest may have formed their own households. If the degree of error is random across block groups, our estimates are biased downward.
} 
Catholic school charges $\$ 2,000$ for the first enrolled sibling, $\$ 1,500$ for the second and $\$ 1,000$ for the third. We define a myopic family as one that decides whether its children will attend private school this year based on the current costs of sending $n_{t}$ children to Catholic school this year. This cost incorporates multiple-child discounts, but only for the $n_{t}$ children of elementary-school age. In our example, the middle and oldest child are of elementary school age but the youngest is not, so the myopic cost in 2000 is $\$ 3,500$, the price charged a family with two simultaneously-enrolled siblings.

We define a forward-looking family as one that decides at the time of the school entry of its firstborn child whether to send all of its $m$ children to private school from grades one through eight. In this model, the salient cost is that of sending $m$ children to private school for eight years. This cost incorporates multiple-child discounts for all $m$ children in the family, whether or not they are currently of elementary-school age. ${ }^{18}$ In the forward-looking model, the salient cost for our sample family is $\$ 39,000$. A forward-looking family may weigh future costs less heavily that present costs (a myopic family is a limiting case, giving future costs a weight of zero). If our sample family discounts the future at a rate of 3 percent a year, their lifetime, discounted tuition cost is $\$ 33,096{ }^{19}$

In the first column of Table 7, we reproduce results from the previous section, now labeling them as “myopic.” In the next two columns we show results for the forward-looking model with discount rates of three percent and zero percent. In all of these specifications, the outcome of interest is the same: whether all of the children who are currently of elementary school age are attending private school. All of the specifications include block-group fixed effects and controls for the ages, spacing and number of children in the family. In the myopic model, the price coefficient in is -0.356 , with a standard error of 0.122. This coefficient suggests that a $\$ 1,000$ increase in current tuition costs (about a third of the average) decreases the probability of private school attendance by 0.36 percentage points. The implied elasticity of catholic school attendance (assuming uncorrelated non-catholic private school prices, as discussed above) is -0.15 .

$18 \quad$ Future tuition schedules are unknown, of course, and we have past tuition schedules for only a subset of our schools. We therefore assume stability of tuition prices. That is, we assume that the family's best forecast of future tuition prices (and our best guess at past prices) is current prices.

19 Here we treat Census 2000 as t=0, discounting any costs going forward and inflating costs going backward. 
In the analogous forward-looking model, with the future discounted at an annual rate of three percent, the price coefficient is -0.44 , with a standard error of 0.123 . The latter coefficient suggests that a $\$ 10,000$ increase in the present-discounted value of lifetime tuition costs (also about a third of the average) decreases the probability of private school attendance by 0.44 percentage points. The implied elasticity here is about $30 \%$ larger, at -0.19 , although it is not significantly different. The model that incorporates no discount rate produces very similar results (-0.40 percentage points). Adding demographics changes none of these results substantially.

Note that present costs are nested within lifetime costs: lifetime costs are the sum of present costs, past costs and future costs. This allows us to test the myopic against the forward-looking models in a straightforward fashion. We execute regressions with two price terms: one for present costs and a second that captures past and future costs. We then test the hypothesis that the coefficient on the second term differs from zero. This test rejects the myopic model; the t-statistic on the sum of present and future costs is significant. The coefficient on the present costs is larger $(-0.196)$ and less precise than that on past and future costs (-0.029). The results suggest that families are indeed sensitive to lifetime costs when making their schooling decisions. We will therefore focus in the rest of the paper on the forward-looking model. Since the undiscounted and discounted forward-looking models produce similar results, we focus on the undiscounted results.

\section{Exogeneity of Multiple-Child Discounts}

Our approach assumes that sibling discounts are set exogenously to neighborhood preferences for private schooling. There are two mechanisms that would violate this assumption. First, schools may set their sibling prices according to perceived differences in demand between smaller and larger families in the neighborhood. Second, large families with a taste for private school may choose to live near schools with large discounts. ${ }^{20}$ Both mechanisms would generate a spatial correlation between family size and the generosity of sibling discounts.

20 If smaller families with a taste for private schooling also live close to schools with large discounts, there is no threat of bias, since the block group fixed effects control for any preferences shared by large and small families. 
In Table 8, we probe the data for such a correlation by testing for a relationship between the magnitude of sibling discounts and the size of nearby families. In this analysis, the unit of observation is the school. The dependent variable captures sibling discounts at the school. We compactly parameterize these discounts in the following way. For each school, we calculate the cost of enrolling three children born two years apart in first through eighth grade. We then calculate a counterfactual "undiscounted" tuition cost for this family, by assuming that each school would charge a flat tuition rate equal to what is now its first-sibling price. We divide the discounted cost by the undiscounted cost, yielding a discounted tuition index that takes value one in a school that offers no sibling discounts. This index averages 0.85 , indicating that the "typical” school discounts lifetime tuition costs by fifteen percent for our hypothesized family. The $25^{\text {th }}$ percentile is 0.74 and the minimum value is 0.45 . One quarter of schools offer no discounts at all and so their value is one.

To test for a correlation between the size of discounts and family size, we regress the schools’ discount index against variables measuring the size of nearby families. ${ }^{21}$ A non-zero coefficient suggests that family size and school discounts are indeed correlated. The unit of observation in these regressions is the school; there are 1,760 in our sample. "Nearby" families are those for whom this school is the closest Catholic school, as we have defined it in the rest of the paper. The right-hand variable of interest measures the share of families with more than one child of elementary school age (all families in the sample have at least one such child); the mean of this variable is 0.36 , while the $50^{\text {th }}$ and $25^{\text {th }}$ percentiles are 0.36 and 0.32 , respectively.

The first column shows the bivariate relationship between the discounted tuition index and family size. The coefficient is -0.048 , with a t-statistic of less than one. We will interpret the practical magnitude of this coefficient shortly (and conclude that it is very, very small). The sign of the coefficient implies that the discounted tuition index is lower where families are larger; that is, discounts are larger where families are larger. However, the sign of the coefficient flips sign (to 0.29) when we control for the demographics 
of nearby families and region fixed effects, implying that discounts are smaller where discounts are larger; the coefficient is still insignificant. ${ }^{22}$

The overall picture from this table is that of a very small coefficient with a very small standard error - that is, a precisely estimated zero. In practical terms, these coefficients are miniscule, as the following calculation shows. Take the largest coefficient (0.29, in Column 2). Its magnitude suggests that an increase of one percentage point in the share of families in a neighborhood with more than one schoolaged child is associated with an increase in the discounted tuition index at the nearest Catholic school of 0.29. At the means of the data, increasing the share of nearby families with more than one child from 0.36 to $0.37^{23}$ is associated with an increase in the discounted tuition index from 0.8500 to 0.8529 $[=0.85+0.01(0.29)]$. This corresponds to about a $\$ 100$ increase in lifetime tuition costs for our imaginary family, from a base of about $\$ 33,000$. We conclude from this analysis that there is no statistically or substantively significant relationship between family composition and the magnitude of tuition discounts.

The coefficients are substantively similar (very small and insignificant ) when we use other metrics of the discounts (second child percentage discount, third child percentage discount) and other metrics of family size (share of families with two children, share of families with three children). These results indicate that there is no systematic relationship between the discounts offered by schools and the size of nearby families. This rules out the following threats to identification: 1 ) schools set discounts based on the size of nearby families 2) large families move near schools with large discounts 3) families have more children when they live near schools with large discounts.

\section{Heterogeneity in Schooling Decisions by Parental Characteristics}

We now examine whether price effects vary across demographic groups. A frequently-vocalized concern is that private schools will "cream” certain students from failing schools. This is, at its heart, a prediction about which students will respond more elastically to the offer of a voucher. We are (obviously) unable to examine how price sensitivity varies by characteristics not observed in Census, such

\footnotetext{
22 We collapse the demographics down to (family-weighted) school-level means in order to include them in this school-level regression.

23 One percentage point is a large increase, as the distribution of this family composition variable is quite compressed: mean $0.36,50^{\text {th }}$ percentile 0.36 and $25^{\text {th }}$ percentile 0.32 .
} 
as the degree of parental involvement in a child's school or a child's previous academic performance. We therefore cannot predict how “creaming” might occur along these dimensions. But we can measure how price sensitivity varies by race/ethnicity, parental education and income. These parameters will allow us to predict how a price subsidy to private school could alter the demographics of public and private schools.

We run pooled regressions in which the price coefficient is allowed to vary across groups. For example, in our income analysis, price is interacted with dummies that indicate whether a family is in the top, middle or bottom of the family income distribution. Each regression also includes main effects for these family characteristics, as well as the interaction of these main effects with the family composition fixed effects. This specification allows the relationship between family composition and private school attendance to vary across demographic groups, while constraining the block-group fixed effects to be the same across subgroups. Loosening this latter restriction does not substantively alter the results, but does decrease precision.

We first examine heterogeneity in price effects by parental education (Table 9, left panel). In our sample, two-thirds of families have a parent with any college education. Families in which neither parent attended college appear to be substantially more responsive to price (coefficient of -0.51 , standard error of 0.13) than families in which a parent has attended college (-0.31, standard error of 0.13$)$. Since the rate of private school attendance is quite low for low-education families (3.2 percent vs. 8.9 percent) the implied elasticity for low-education families (-0.51) is above five times that for highly-educated families (-0.11). These elasticities are statistically distinguishable at conventional levels. ${ }^{24}$ The results indicate that vouchers would tend to increase the share of private school students who come from families with relatively low levels of parental education.

We next examine heterogeneity in price effects by parental race and ethnicity (Table 9, middle panel). We divide the population into three mutually-exclusive groups: Hispanics of any race, Black nonHispanics and White non-Hispanics. Hispanics have a relatively low rate of Catholic school attendance;

$24 \quad$ To calculate standard errors for the elasticities, we make the simplifying assumption that the means of tuition prices and private school attendance are population values rather than random variables. Under this assumption, the elasticities have the same statistical significance as the price coefficients, since the price coefficient is the only term in the price elasticity that has sampling variation. 
3.6 percent send their children to Catholic school, compared to five percent for Black non-Hispanics and 8.1 percent for White non-Hispanics. Interestingly, Catholic school prices faced by Hispanics are about ten percent higher than those faced by the rest of the population.

White, non-Hispanic families are substantially more responsive to price: their coefficient is -0.39 , as compared to -0.01 for Black, non-Hispanics and -0.19 for Hispanics. The latter two coefficients are not statistically distinguishable from zero. The implied elasticities are -0.16 (White non-Hispanics), 0.01 (Black non-Hispanics) and -0.20 (Hispanics). This is the one case when allowing the block-group effects to vary by subgroup has a non-trivial effect on the results: the Hispanic and Black coefficients flip sign, but remain insignificant (results not shown). The one unambiguous pattern that persists across specifications is that White non-Hispanics appear to be more price-elastic than Black non-Hispanics, though this difference is not always statistically significant.

Private school attendance rises with income. Ten percent of those in the top third of the income distribution send their children to Catholic school, as compared to seven and four percent in the middle and low-income groups, respectively (Table 9, rightmost panel). We estimate price coefficients for middle- and low-income families that are statistically significant and large (-0.59 and -0.48 , respectively), while for high-income families the effect is smaller and insignificant (-0.26). The price elasticities implied by these coefficients drop monotonically with income: $-0.44,-0.27$ and -0.09 for low-, medium- and highincome families, respectively. These results suggest that vouchers would increase the representation of low- and middle-income families at private schools.

We would expect that Catholic families are those most likely to take up the option of Catholic schooling. It is theoretically ambiguous, however, whether Catholics would be more or less sensitive to our identifying variation in price. On the one hand, Catholics may have such a strong preference for religious education that they are insensitive to price. On the other hand, Catholics may be most knowledgeable about (and therefore more responsive to) the sibling discounts. Catholics cannot be identified in the Census; the US government is legally barred from asking about religious affiliation in its 
surveys. Ethnicity is gathered, however, and this information can be used to predict religious affiliation. ${ }^{25}$ We define terciles of the predicted probability of being Catholic (roughly, >60 percent, 20-60 percent, $<20$ percent).

The data support the hypothesis that Catholics are more sensitive to Catholic school prices (Table 10). Among those with the highest predicted probability of being Catholic, the price coefficient is -0.74 , as compared to -0.12 and -0.08 for those with medium and low probability of being Catholic. The elasticities are $-0.36,-0.04$ and -0.05 , respectively, with only the first distinguishable from zero. Note that these results provide support for the assumption (discussed earlier in the paper) that the variation in private school attendance and price drives indentifies our parameters is variation in Catholic school attendance and Catholic school price.

As a compact way to summarize our predicted effects of vouchers on the demographic composition of private and public schools, we interact price with the predicted probability that a family will send its children to private school. We use demographics (race, ethnicity, income, parents' education and marital status) to estimate a probit equation in which the outcome is dummy for a family's private school attendance. From these estimated coefficients we generated a predicted probability of private school attendance for each family. We then interacted dummies representing terciles of these predicted probabilities with the price variable in our preferred specification. We also include the tercile dummies as controls, as well as the interactions of the dummies with the family composition fixed effects.

The results (Table 10) indicate that families with the highest predicted probability of private school attendance are the least sensitive to price. The elasticity drops monotonically as the predicted probability of private school attendance drops: -0.09 for families most likely to attend private school, 0.28 for families in the middle of the predicted probability distribution, and -0.59 for families who are least likely to attend private school. These elasticities are statistically distinguishable from each other. These results suggest that a voucher program would disproportionately induce into private schools those who, along observable dimensions such as race, ethnicity, income and parental education, are dissimilar

\footnotetext{
25 We use the method of Gruber $(2004,2005)$ to generate for each family a predicted probability of being Catholic, using data from the General Social Survey, which does collect religious affiliation. This predicted probability is simply the share of the family's ethnic group that self-indentifies as Catholic in the GSS. We limit the sample to non-Asian whites for this analysis.
} 
from those who currently attend private school. This is in marked contrast to the assumption made in previous studies (e.g., Figlio and Stone; Lankford and Wyckoff) that the new students that vouchers would induce into private school would look demographically similar to current private school students.

\section{Conclusion}

In the private schooling market, prices and quantities are equilibrium outcomes, the product of shifts along both the supply curve and demand curve. An exogenous source of variation in tuition prices is needed in order to estimate the price elasticity of demand for private school attendance. We exploit a unique and unexploited source of variation in tuition prices to estimate this price elasticity. The majority of Catholic elementary schools offer sibling discounts. These discounts reduce schooling costs for families that, in a given year, enroll more than one child in a single Catholic school. The discounts are set by individual schools and vary considerably.

As a result of these non-linear pricing schedules, a family's tuition costs are a function of the interaction of the number and spacing of their children with the pricing policies of the local Catholic school. We have collected data on these discounts from schools representing over half of Catholic school enrollment in the US. Within-neighborhood variation in tuition prices allows us to include in our demand equation extremely fine geographic fixed effects, thereby controlling for unobserved determinants of demand that vary across neighborhoods. Restricted-use Census data allows us to identify households at levels of geography down to the block. We also control flexibly for the number and spacing of children in each family, thereby absorbing any underlying relationship between family composition and private school attendance.

We find that a standard deviation decrease in tuition prices increases the probability that a family will send its children to private school by one half to one percentage point. This translates into an elasticity of the probability of private school attendance with respect to tuition costs of -0.19 . Our average effect masks substantial heterogeneity in the response to price. Families with lower levels of parental education are about over four times as price elastic than other families. The price elasticity of private school attendance drops monotonically with income; it is -0.44 in the bottom tercile but near zero in the top tercile. Overall, it is those families who (along observable dimensions) are least like the current 
population of private school customers that are most sensitive to price, suggesting that vouchers would substantially alter the socioeconomic composition of private schools.

The offer of a voucher to students in a failing public school may well be a complex combination of "treatments": the spotlight of public attention, intervention by higher levels of government in school governance, as well as a discount at a local private (or public) school. Our estimates capture only the last causal channel. But our results strongly suggest that a voucher program would disproportionately induce into private schools those who, along observable dimensions such as race, ethnicity, income and parental education, are dissimilar from those who currently attend private school. 


\section{Data Appendix}

\section{Tuition Data}

In September of 2002, we began to contact Catholic dioceses, which are the sub-national administrative unit of the Catholic Church. A letter from the National Catholic Education Association, indicating its support for our efforts, was presented during these initial contacts. In our communications with dioceses we requested schools’ zip codes, grades taught (e.g. K-5, K-8, 9-12), total enrollment, enrollment of Catholic and non-Catholic students, and tuition schedules.

By December 2003, all 168 dioceses had been contacted by letter or e-mail at least three times and by phone at least twice. Ultimately, 45 dioceses declined to participate (29\% of national enrollment), 60 agreed to participate and sent data (37\% of national enrollment). An additional 31 agreed to participate but despite repeated reminders and confirmation of their intent have not sent data ( $24 \%$ of national enrollment). The remaining never responded to any of the written data requests or returned any of the multiple voice mail messages (10\% of national enrollment). Those that declined to participate overwhelmingly cited staffing constraints or lack of data as the reason.

The data from the dioceses arrived in multiple formats: piles of paper, spreadsheets, and wordprocessing files. Research assistants (double) entered these data into a computer. Our sample tilts toward large dioceses, both because we pursued their participation most aggressively and because the smaller dioceses frequently did not have the personnel and record keeping to allow them to respond to our request without unduly burdening their staff. In several cases research assistants traveled to a diocese to enter data from paper records into a laptop when the diocese was unwilling to send us records. This was worthwhile only for large dioceses. 


\section{Merging Census with Tuition Data}

We match our detailed tuition data to census blocks in the 2000 Census. Our matching process is as follows:

1) Calculate latitudes and longitudes for the physical location of all Catholic schools.

We used mapping software to calculate the latitude and longitude of every Catholic school in the country (not just those in our tuition sample), drawing on the census of Catholic schools contained in the US Department of Education's Private School Survey.

2) Obtain latitudes and longitudes of population-weighted block centroids from Census Bureau.

3) Calculate distance from each block to every elementary Catholic school located in the same state This was necessary to limit the number of calculations.

4) Discard blocks for which distance to the closest Catholic elementary school is greater than ten miles.

5) Assign to each block the Catholic elementary school closest to the block centroid (as the crow flies).

6) Discard blocks for which the closest Catholic elementary school is not a K-8 school or is not in our tuition dataset. 


\section{REFERENCES}

Altonji, Joseph G., Todd E. Elder, and Christopher R. Taber (2005). "An Evaluation of Instrumental Variable Strategies for Estimating the Effects of Catholic Schooling." Journal of Human Resources, 40:4, 791-821.

Altonji, Joseph G., Todd E. Elder, and Christopher R. Taber (2005). "Selection on Observed and Unobserved Variables: Assessing the Effectiveness of Catholic Schools." Journal of Political Economy, 113, 151-184.

Buddin, Richard J., Joseph J. Cordes and Sheila Nataraj Kirby (1998) "School Choice in California: Who Chooses Private Schools?" Journal of Urban Economics, 44:1, 110-134.

Calvo, Naomi (2007) "How parents choose schools: a mixed-methods study of public school choice in Seattle.” Ph.D. Dissertation, Harvard University.

Chiswick, Barry and Stella Koutroumanes (1996) "An Econometric Analysis of the Demand for Private Schooling," Research in Labor Economics, 15, 209-237.

Coleman, James, Thomas Hoffer and Sally Kilgore (1982) High school achievement: Public, Catholic and Private Schools Compared. New York: Basic Books.

Downes, Thomas A. and Shane M. Greenstein (1996) "Understanding the Supply Decisions of Nonprofits: Modeling the Location of Private Schools," RAND Journal of Economics 27:2, 365390.

Downes, Thomas A. and Shane M. Greenstein (2002) "Entry into the Schooling Market: How is the Behaviour of Private Suppliers Influenced by Public Sector Decisions?" Bulletin of Economic Research 54:4, 341-371.

Downes, Thomas A. and Jeffrey E. Zabel (2002) "The impact of school characteristics on house prices: Chicago 1987-1991, " Journal of Urban Economics, 52:1, 1-25.

Epple, Dennis and Richard E. Romano (1998) "Competition between Private and Public Schools, Vouchers, and Peer-Group Effects," The American Economic Review, 88:1, 33-62.

Epple, Dennis and Richard Romano (2002) "Educational Vouchers and Cream Skimming," NBER Working Paper 9354.

Eriksen, O. Homer (1982) "Equity Targets in School Finance, Tuition Tax Credits, and the Public-Private Choice," Journal of Education Finance, 7:4, 436-49.

Figlio, David N. and Cecilia Elena Rouse (2006) "Do accountability and voucher threats improve lowperforming schools?" Journal of Public Economics, 90:1-2, 239-255. 
Figlio, David N. and Joe A. Stone (2001) "Can Public Policy Affect Private School Cream Skimming?" Journal of Urban Economics, 49:2, 240-266.

Glazerman, Steven (1998) "Determinants and Consequences of Parental School Choice." Dissertation Thesis, University of Chicago, Chicago.

Gruber, Jonathan (2004) "Pay or Pray? The Impact of Charitable Subsidies on Religious Attendance," Journal of Public Economics, 88:12, 2635-2655.

Gruber, Jonathan (2005) "Religious Market Structure, Religious Participation and Outcomes: Is Religion Good for You?," Advances in Economic Analysis and Policy5:1,

Hastings, Justine S., Thomas J. Kane, and Douglas O. Staiger. 2005. "Parental Preferences and School Competition: Evidence from a Public School Choice Program.” NBER Working Paper No. 11805.

Howell, W.G, Wolf, P. J., Campbell, D. E., \& Peterson, P. E. (2002). School Vouchers and Academic Performance: Results from Three Randomized Field Trials. Journal of Policy Analysis and Management, 21(2), 191-217.

Imbens, Guido and Joshua Angrist (1994) "Identification and Estimation of Local Average Treatment Effects" Econometrica 62:2, pp. 467- 475.

Kane, Thomas J., Stephanie K. Riegg and Douglas O. Staiger (2006) "School Quality, Neighborhoods, and Housing Prices," American Law \& Economics Review, 8:2, 183-212.

Keeler, A. and W. Kriesel (1994) "School Choice in Rural Georgia: An Empirical Analysis," Journal Of Agricultural And Applied Economics, 26:2.

Kealey, Robert (1993) “Stewardship and the Catholic School Tuition Program,” Washington, DC: National Catholic Educational Association.

Kealey, Robert (2002) "Balance Sheet for Catholic Elementary Schools: 2001 Income and Expenses,” Washington, DC: National Catholic Educational Association.

Krueger, Alan and Pei Zhu (2004) "Another Look at the New York City School Voucher Experiment," American Behavioral Scientist. 47:5, 658-98.

Lankford, Hamilton and James Wyckoff (1992) "Primary and secondary school choice among public and religious alternatives," Economics of Education Review, 11:4, 317-337.

Lankford, Hamilton and James Wyckoff (2001) "Who Would Be Left Behind by Enhanced Private School Choice?" Journal of Urban Economics, 50:2, 288-312. 
Long, James E. and Eugenia F. Toma (1988) "The Determinants of Private school attendance, 19701980," The Review of Economics and Statistics, 70:2, 351-357.

Mayer, Daniel, Paul Peterson, David Myers, Christina Clark Tuttle and William Howell (2002) "School Choice in New York City After Three Years: An Evaluation of the School Choice Scholarships Program," Mathematica Policy Research Report.

Neal, Derek (1997) "The Effect of Catholic Secondary Schooling on Educational Achievement," Journal of Labor Economics, 15:1, 98-123.

Neal, Derek (2002) "How Vouchers Could Change the Market for Education," The Journal of Economic Perspectives, 16:4, 25-44.

Oates, W.E. (1969) "The effects of property taxes and local public spending on property values: An empirical study of tax capitalization and the Tiebout hypothesis," Journal of Political Economy, 77, 957-971.

Peltzman, Sam (1973) "The Effect of Government Subsidies-in-Kind on Private Expenditures: The Case of Higher Education," The Journal of Political Economy, 81:1, 1-27.

Rouse, Cecilia Elena (1998) "Private School Vouchers and Student Achievement: An Evaluation of the Milwaukee Parental Choice Program," The Quarterly Journal of Economics, 113: 2, 553-602.

Stiglitz, Jospeh. E. (1974) "The demand for education in public and private school systems," Journal of Public Economics, 3:4, 349-385.

US Conference of Catholic Bishops "U.S. Catholic Dioceses," retrieved on January 24, 2007 from $<$ http://www.usccb.org/dioceses.htm>.

US Conference of Catholic Bishops " Catholic Elementary and Secondary Schools: 2004-2005," retrieved on January 30, 2007 from < http://www.nccbuscc.org/education/fedasst/statistics.shtml>.

US Department of Education (2002) "Paige Issues Statement On Today's Supreme Court Decision On School Choice," Press release, retrieved on January 25, 2007 from <http://www.ed.gov/news/pressreleases/2002/06/06272002d.html>.

US Department of Education (2004) Digest of Education Statistics.

US Department of Education National Center for Education Statistics (2006) Characteristics of Private Schools in the United States: Results From the 2003-2004 Private School Universe Survey.

Witte, John F. and Christopher A. Thorn (1996) "Who Chooses? Voucher and Interdistrict Choice Programs in Milwaukee," American Journal of Education, 104:3, 186-217. 
Figure 1A

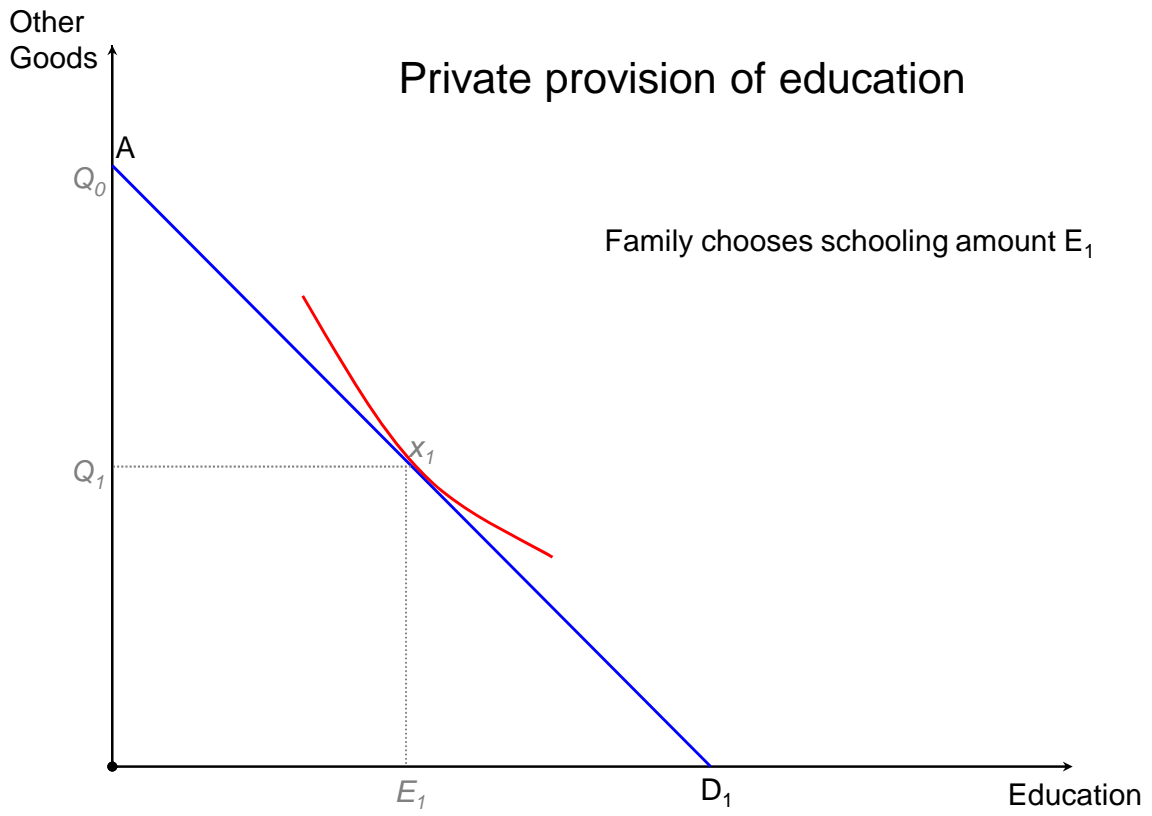

Figure 1B

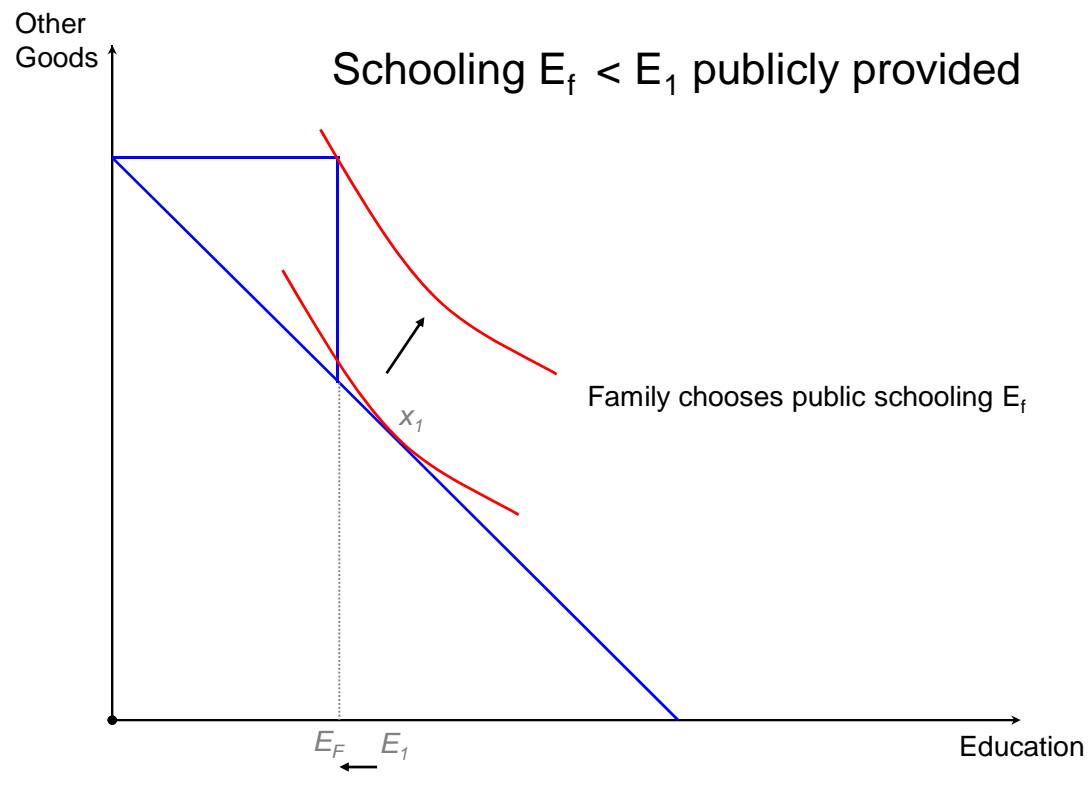

S 
Figure 1C

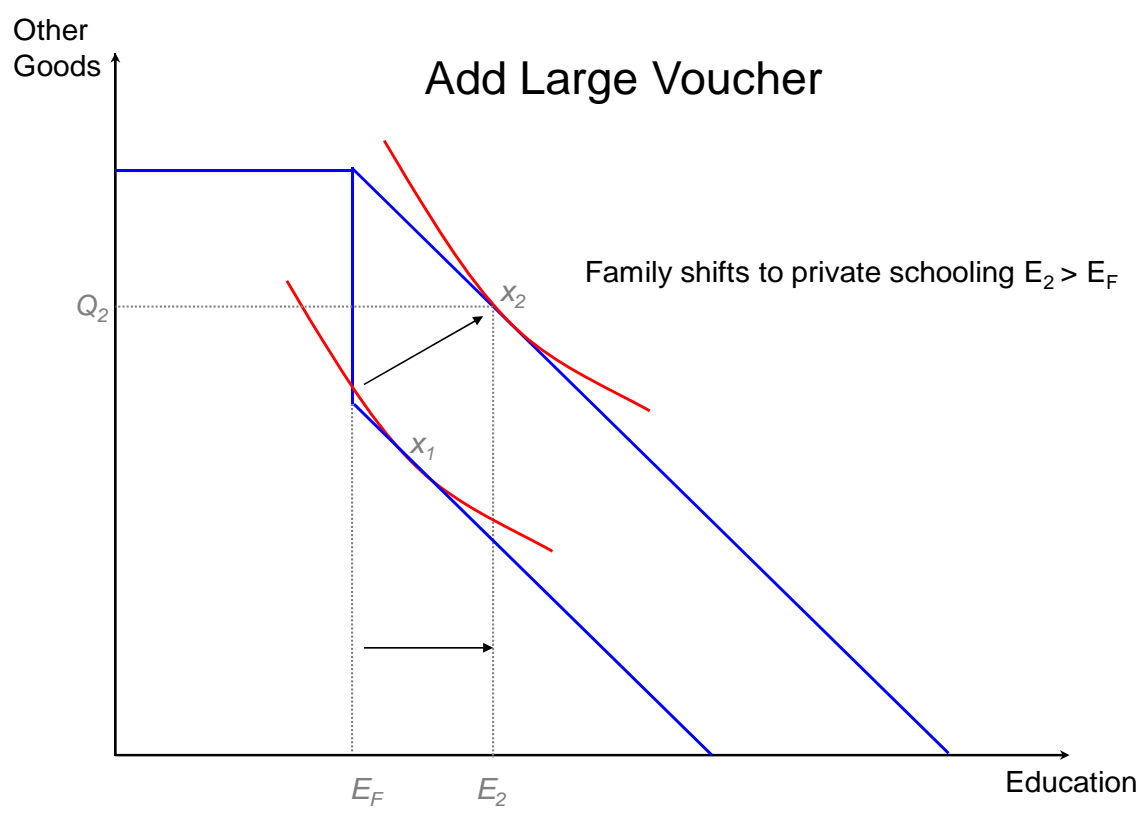

Figure 1D

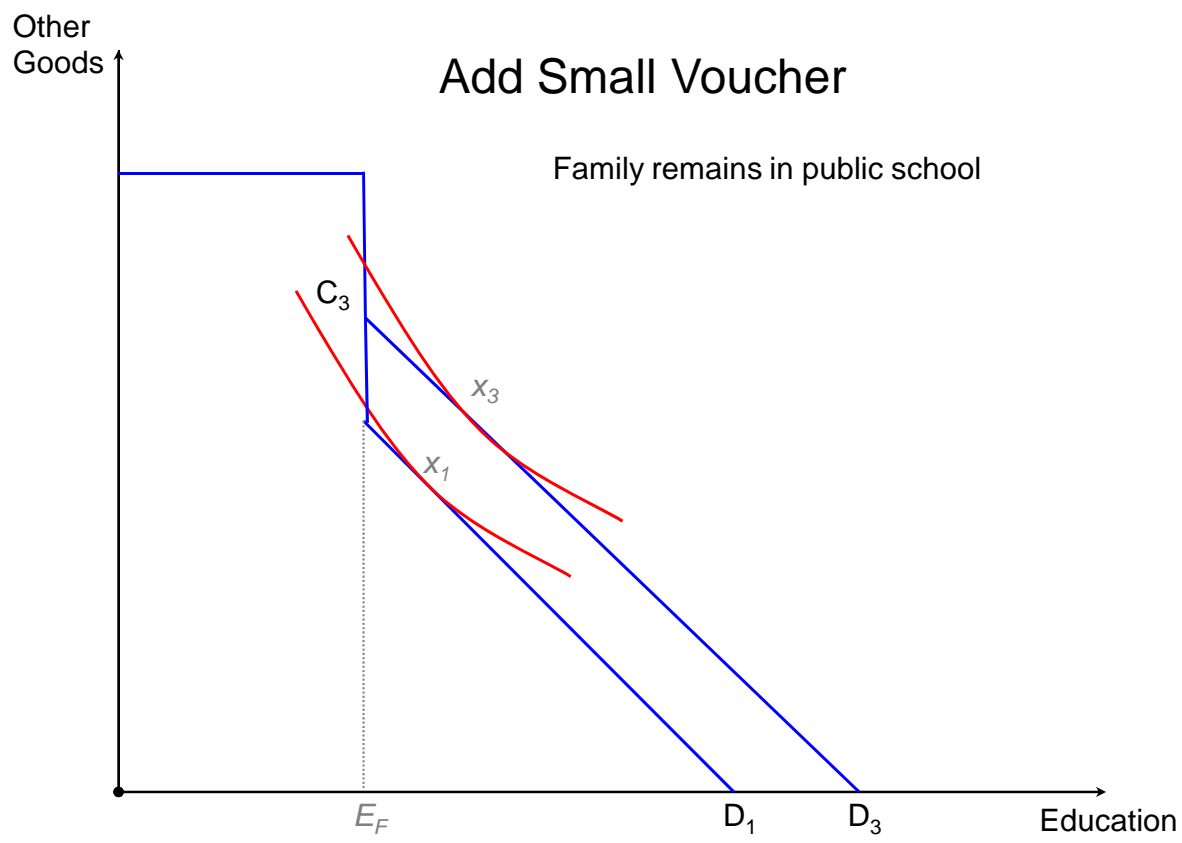


Figure 1E

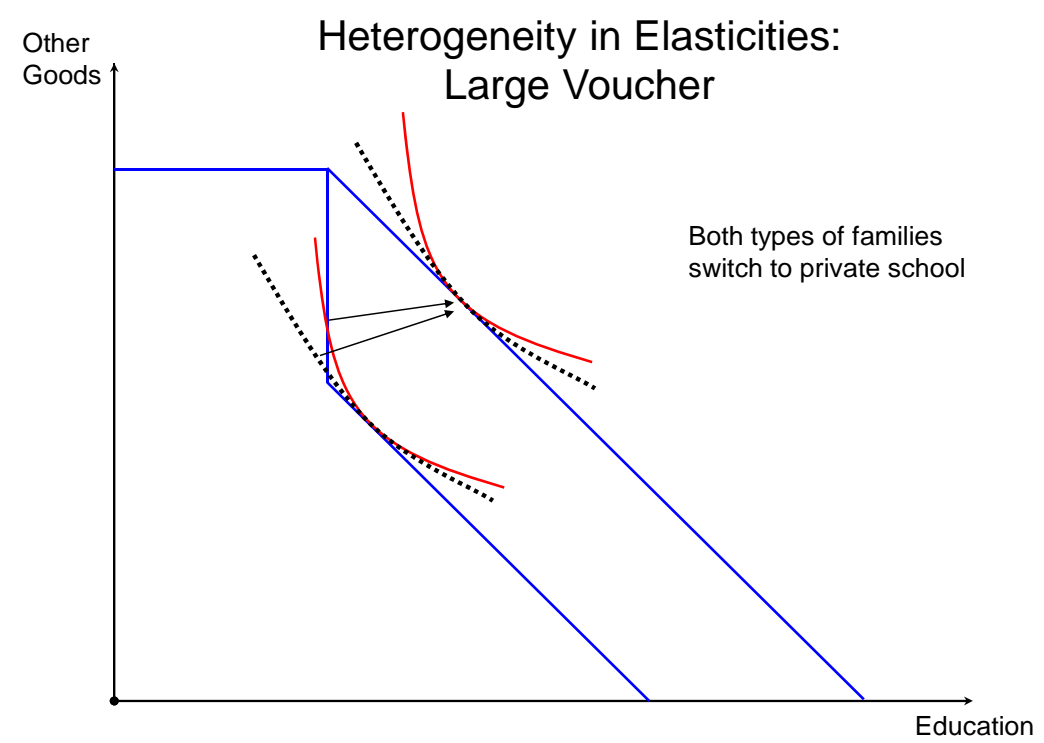

Figure 1F

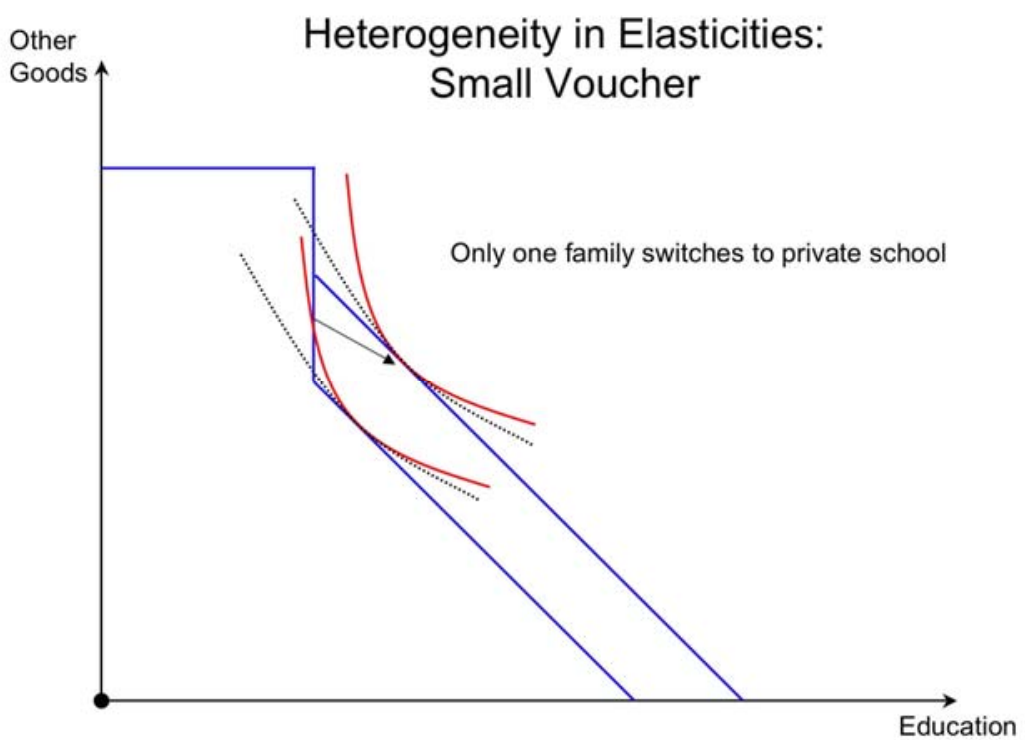


Figure 2

Distribution of Catholic Dioceses and Tuition Sample

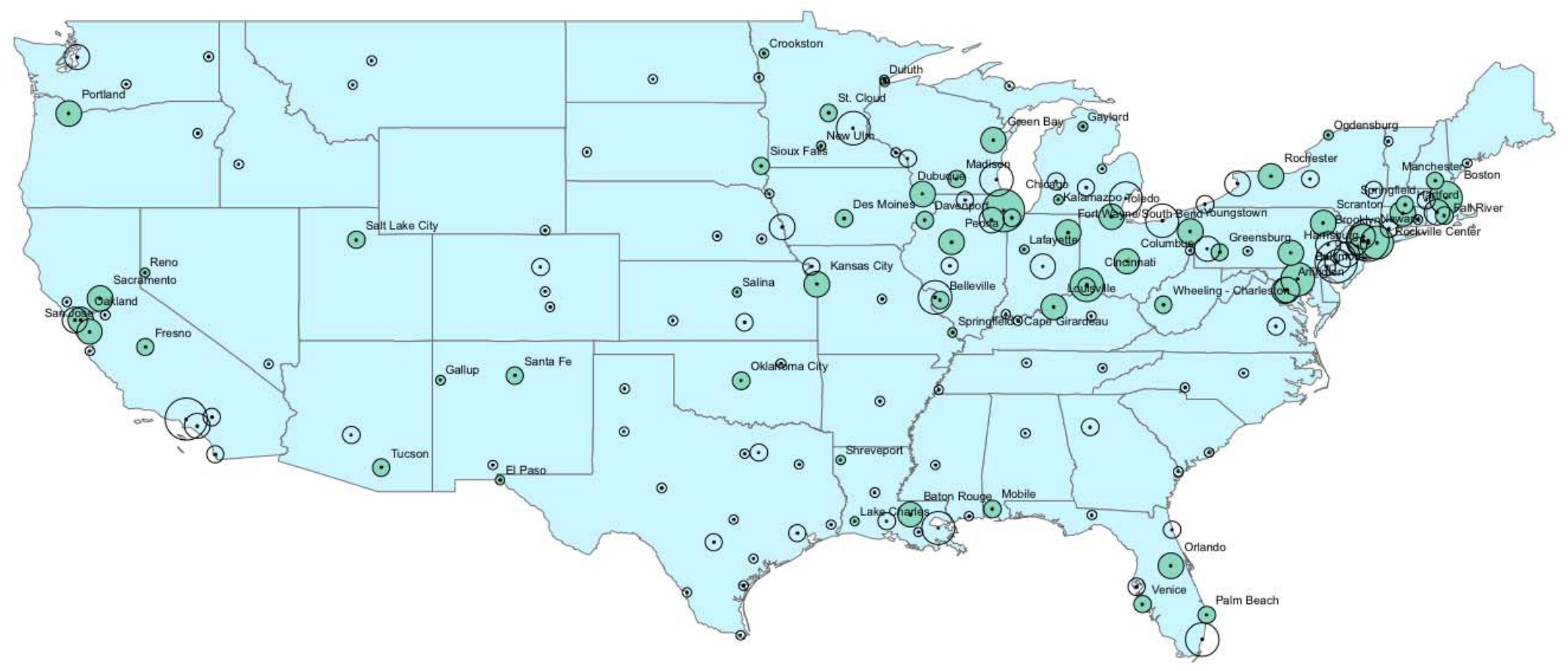

Note:

Green circles are dioceses in the sample, with diameter proportional to Catholic school enrollment in the diocese. Blue dots are dioceses not in sample 
Table 1

Sibling Discounts at Two Schools in Columbus, Ohio

\begin{tabular}{lcc}
\hline & “Blessed Sacrament” & “St. Catherine’s” \\
\hline Tuition, ${ }^{\text {st }}$ Sibling & $\$ 1,200$ & $\$ 1,125$ \\
Tuition, ${ }^{\text {nd }}$ Sibling & $\$ 1,200$ & $\$ 325$ \\
Tuition, $3^{\text {rd }}$ Sibling & $\$ 1,200$ & 0 \\
\hline
\end{tabular}

Table 2

Catholic Elementary School Tuition Schedules

1999-2000 Academic Year

Weighted by \# nearby students

$\mathrm{N}=1760$

\begin{tabular}{cccccc}
\hline $\begin{array}{c}\text { Tuition Charged for } \\
\text { Sibling Number.. }\end{array}$ & Mean & $\begin{array}{c}25^{\text {th }} \\
\text { percentile }\end{array}$ & $5^{\text {th }}$ percentile & $7^{\text {th }}$ percentile & SD \\
1 & 1,975 & 1,550 & 1,997 & 2,350 & 700 \\
2 & 1,473 & 965 & 1,400 & 1,860 & 743 \\
3 & 1,258 & 680 & 1,135 & 1,720 & 1,258 \\
4 & 1,103 & 450 & 1,000 & 1,677 & 899 \\
\hline
\end{tabular}

Source: Data collected by authors. 
Table 3

Shares of Schools Offering Various Sibling Discount Rates

1999-2000 Academic Year

Weighted by \# nearby students

$\mathrm{N}=1,760$

\begin{tabular}{cccccccc}
\hline $\begin{array}{c}\text { Discount } \\
\text { Offered } \\
\text { Sibling \#: }\end{array}$ & None & $\begin{array}{c}1 \% \text { to } \\
10 \%\end{array}$ & $\begin{array}{c}10 \% \text { to } \\
25 \%\end{array}$ & $\begin{array}{c}25 \% \text { to } \\
50 \%\end{array}$ & $\begin{array}{c}50 \% \text { to } \\
75 \%\end{array}$ & $\begin{array}{c}75 \% \text { to } \\
90 \%\end{array}$ & $\begin{array}{c}90 \% \text { to } \\
100 \%\end{array}$ \\
\hline 2 & 0.48 & 0.06 & 0.1 & 0.21 & 0.11 & 0.02 & 0.01 \\
3 & 0.31 & 0.01 & 0.08 & 0.19 & 0.29 & 0.08 & 0.03 \\
4 & 0.31 & 0.01 & 0.06 & 0.13 & 0.22 & 0.08 & 0.17 \\
\hline
\end{tabular}

Table 4

Difference-in-Difference in Family Tuition Costs

Two Schools in Columbus, Ohio

\begin{tabular}{cccc}
\hline & One Child Enrolled & Two Children Enrolled & Difference \\
\hline St. Catherine's & 1125 & 1450 & 325 \\
Blessed Sacrament & 1200 & 2400 & 1200 \\
Difference & 75 & 950 & $\mathbf{8 7 5}$ \\
\hline
\end{tabular}


Table 5 : Sample Characteristics

2000 Household Census Microdata, 1-in-6 Sample

Families with 1-3 children aged 6-13, no more than 6 children aged 0-18 Means are family-weighted

Full Sample Households located within 10 miles of school in Catholic school sample

(1)

(2)

\section{Family Characteristics}

All children 6-13 in private school

0.078

0.134

Either Parent Black or Hispanic

0.285

0.285

Either Parent Attended College

0.623

0.678

Northeast

0.182

0.297

South

0.332

0.191

West

0.210

0.208

Midwest

0.276

0.305

Urban Area

0.571

0.836

Urban Cluster

0.106

0.056

Non Urban

0.323

0.108

Number of Children 0-18

2.54

2.32

(0.987)

Number of Children 6-13

1.59

1.68

(0.678)

(0.685)

Family Size

4.42

4.22

(1.288)

Household Income

62,536

72,678

$(72,378)$

$(85,464)$

Sample Size

Blocks

Block Groups

$1,736,984$

266,380

Families

206,703

42,266

Children Age 0-18

2,969,515

463,505

Children Age 6-13

$6,465,053$

979,571

$4,235,364$

658,832 
Table 6: Baseline Analysis

Dependent variable: All children in family attend private school

Total cost: Annual cost of sending all children in family to nearest Catholic school

Unit of observation is a family $(\mathrm{N}=463,505)$

\begin{tabular}{|c|c|c|c|c|c|c|c|}
\hline \multirow{3}{*}{$\begin{array}{l}\text { FE for ages \& spacing of children? } \\
\text { Demographics? }\end{array}$} & \multicolumn{3}{|c|}{$\begin{array}{l}\text { No Geographic } \\
\text { Fixed Effects }\end{array}$} & \multicolumn{2}{|c|}{$\begin{array}{c}\text { Tract } \\
\text { Fixed Effects } \\
{[16,609]}\end{array}$} & \multicolumn{2}{|c|}{$\begin{array}{c}\text { Block Group } \\
\text { Fixed Effects } \\
{[42,226]}\end{array}$} \\
\hline & & $\mathrm{Y}$ & $\mathrm{Y}$ & $\mathrm{Y}$ & $\mathrm{Y}$ & $\mathrm{Y}$ & $\mathrm{Y}$ \\
\hline & & & $\mathrm{Y}$ & & $\mathrm{Y}$ & & $\mathrm{Y}$ \\
\hline & (1) & (2) & (3) & (4) & (5) & (6) & (7) \\
\hline Total Cost $(\$ 1000)$ & $\begin{array}{l}-0.072 \\
(0.056)\end{array}$ & $\begin{array}{c}0.454 \\
(0.080)\end{array}$ & $\begin{array}{c}-0.049 \\
(0.075)\end{array}$ & $\begin{array}{l}-0.235 \\
(0.104)\end{array}$ & $\begin{array}{c}-0.295 \\
(0.100)\end{array}$ & $\begin{array}{l}-0.356 \\
(0.122)\end{array}$ & $\begin{array}{l}-0.377 \\
(0.117)\end{array}$ \\
\hline $\mathrm{R}^{2}$ & 0.000 & 0.003 & 0.05 & 0.133 & 0.17 & 0.207 & 0.235 \\
\hline
\end{tabular}

Coefficients indicate percentage point change in probability of private school attendance associated with a $\$ 1000$ increase in price. Number of geographic fixed effects in brackets. Where indicated, regressions include fixed effects for ages of children and age difference between adjacent siblings. Demographics consist of dummies for: mother's and father's education (less than high school, high school, some college, college grad); presence of mother and father; mother's and father's marital status; mother's and father's race and ethnicity; family income ( $\$ 10 \mathrm{~K}$ brackets, with $\$ 200 \mathrm{~K}+$ a single bracket). Heteroskedasticity-robust standard errors allow for correlation within block groups. 
Table 7: Alternative Pricing Models

Dependent variable: All children in family attend private school

Unit of observation is a family $(\mathrm{N}=463,505)$

\begin{tabular}{|c|c|c|c|}
\hline & Myopic Model & $\begin{array}{c}\text { Forward-Looking } \\
\text { Model } \\
\text { Discount Rate = } \\
3 \%\end{array}$ & $\begin{array}{c}\text { Forward-Looking } \\
\text { Model } \\
\text { Discount Rate }=0\end{array}$ \\
\hline & $(1)$ & $(2)$ & (3) \\
\hline Total Price & $\begin{array}{l}-0.366 \\
(0.126)\end{array}$ & $\begin{array}{l}-0.444 \\
(0.123)\end{array}$ & $\begin{array}{l}-0.400 \\
(0.126)\end{array}$ \\
\hline $\begin{array}{l}\text { Implied Elasticity of Catholic School } \\
\text { Attendance }\end{array}$ & $\begin{array}{l}-0.15 \\
(0.05)\end{array}$ & $\begin{array}{l}-0.21 \\
(0.06)\end{array}$ & $\begin{array}{l}-0.19 \\
(0.06)\end{array}$ \\
\hline Mean of Price Variable & $\$ 2,926$ & $\$ 33,096$ & $\$ 32,953$ \\
\hline Catholic School Attendance Rate (\%) & 7.1 & 7.1 & 7.1 \\
\hline $\mathrm{R}^{2}$ & 0.207 & 0.207 & 0.207 \\
\hline & & \multicolumn{2}{|c|}{$\begin{array}{l}\text { Test Forward-Looking Model } \\
\text { against Myopic Model }\end{array}$} \\
\hline Present Costs $(\$ 1000)$ & & $\begin{array}{l}-0.152 \\
(0.136)\end{array}$ & $\begin{array}{l}-0.196 \\
(0.137)\end{array}$ \\
\hline Past and Future Costs $(\$ 1000)$ & & $\begin{array}{l}-0.037 \\
(0.014)\end{array}$ & $\begin{array}{l}-0.029 \\
(0.015)\end{array}$ \\
\hline $\mathrm{R}^{2}$ & & 0.207 & 0.207 \\
\hline
\end{tabular}

Coefficients indicate percentage point change in probability of private school attendance associated with a $\$ 1,000$ increase in price (myopic model) or $\$ 10,000$ increase in price (forward-looking models). The bottom panel reports coefficients from a regression including separate terms for present and all other costs. A significant coefficient on past and future costs rejects the hypothesis that families are myopic in their price-sensitivity. All specifications contain block-group fixed effects and controls for number, spacing and ages of children. Heteroskedasticity-robust standard errors allow for correlation within block groups. 
Table 8: Are Sibling Discounts Correlated with Family Size?

Dependent variable: Discounted Tuition Index [=(discounted price/undiscounted price)]

Mean of Dependent Variable: 0.85

Mean of Independent Variable: 0.36

Demographics? $\quad$ Y

(1)

$-0.048$

$(0.063)$

1760

1760
0.286

(0.197)

Coefficients indicate the change in the discount index at the nearest Catholic school associated with a onepercentage point increase in the share of nearby families with more than one child. Demographics consist of dummies for: mother's and father's education (less than high school, high school, some college, college grad); presence of mother and father; mother's and father's marital status; mother's and father's race and ethnicity; family income ( $\$ 10 \mathrm{~K}$ brackets, with $\$ 200 \mathrm{~K}+$ a single bracket). 
Table 9 Heterogeneity in Price Effects, by Family Characteristics

Price Interactions

\begin{tabular}{|c|c|c|c|c|c|c|c|c|}
\hline & $\begin{array}{c}\text { Parents } \\
\text { Any } \\
\text { College } \\
\end{array}$ & $\begin{array}{c}\text { Parents } \\
\text { No } \\
\text { College } \\
\end{array}$ & $\begin{array}{c}\text { White } \\
\text { non- } \\
\text { Hispanic }\end{array}$ & $\begin{array}{c}\text { Black } \\
\text { non- } \\
\text { Hispanic }\end{array}$ & $\begin{array}{l}\text { Hispanic, } \\
\text { Any Race }\end{array}$ & $\begin{array}{c}\text { Top } \\
\text { Income } \\
\text { Tercile }\end{array}$ & $\begin{array}{l}\text { Middle } \\
\text { Income } \\
\text { Tercile } \\
\end{array}$ & $\begin{array}{c}\text { Bottom } \\
\text { Income } \\
\text { Tercile } \\
\end{array}$ \\
\hline Price Coefficient & $\begin{array}{l}-0.31 \\
(0.13)\end{array}$ & $\begin{array}{l}-0.51 \\
(0.13)\end{array}$ & $\begin{array}{l}-0.39 \\
(0.14)\end{array}$ & $\begin{array}{c}0.01 \\
(0.18)\end{array}$ & $\begin{array}{l}-0.19 \\
(0.18)\end{array}$ & $\begin{array}{l}-0.26 \\
(0.17)\end{array}$ & $\begin{array}{l}-0.59 \\
(0.15)\end{array}$ & $\begin{array}{l}-0.48 \\
(0.14)\end{array}$ \\
\hline $\begin{array}{l}\text { Implied Elasticity of Catholic School } \\
\text { Attendance }\end{array}$ & $\begin{array}{l}-0.11 \\
(0.05)\end{array}$ & $\begin{array}{l}-0.51 \\
(0.13)\end{array}$ & $\begin{array}{l}-0.15 \\
(0.06)\end{array}$ & $\begin{array}{c}0.01 \\
(0.12)\end{array}$ & $\begin{array}{l}-0.20 \\
(0.19)\end{array}$ & $\begin{array}{l}-0.09 \\
(0.06)\end{array}$ & $\begin{array}{l}-0.27 \\
(0.07)\end{array}$ & $\begin{array}{l}-0.44 \\
(0.16)\end{array}$ \\
\hline Mean of Price Variable & $\$ 30,986$ & $\$ 32,282$ & $\$ 32,017$ & $\$ 33,881$ & $\$ 37,199$ & $\$ 34,731$ & $\$ 31,530$ & $\$ 32,651$ \\
\hline Catholic School Attendance Rate (\%) & 8.9 & 3.2 & 8.1 & 5.0 & 3.6 & 10.3 & 7.0 & 3.6 \\
\hline
\end{tabular}

Each panel is a single regression. All specifications contain block-group fixed effects, subgroup main effects, family structure effects, and the interactions of subgroup effects with family structure effects. Heteroskedasticity-robust standard errors allow for correlation within block groups. 
Table 10: Heterogeneity in Price Effects, by Family Characteristics

Price Interactions

\begin{tabular}{|c|c|c|c|c|c|c|}
\hline & \multicolumn{3}{|c|}{$\begin{array}{l}\text { Predicted Probability Catholic } \\
\qquad \text { N=318,582 }\end{array}$} & \multicolumn{3}{|c|}{$\begin{array}{c}\text { Predicted Probability Children } \\
\text { Attend Private School } \\
\text { N=440,343 }\end{array}$} \\
\hline & High & Middle & Low & High & Middle & Low \\
\hline Price Coefficient & $\begin{array}{l}-0.74 \\
(0.22)\end{array}$ & $\begin{array}{c}-0.12 \\
(0.19)\end{array}$ & $\begin{array}{l}-0.08 \\
(0.22)\end{array}$ & $\begin{array}{l}-0.29 \\
(0.16)\end{array}$ & $\begin{array}{c}-0.64 \\
(0.15)\end{array}$ & $\begin{array}{l}-0.50 \\
(0.13)\end{array}$ \\
\hline Implied Elasticity of Catholic School Attendance & $\begin{array}{l}-0.36 \\
(0.10)\end{array}$ & $\begin{array}{l}-0.04 \\
(0.07)\end{array}$ & $\begin{array}{l}-0.05 \\
(0.10)\end{array}$ & $\begin{array}{l}-0.09 \\
(0.05)\end{array}$ & $\begin{array}{l}-0.28 \\
(0.07)\end{array}$ & $\begin{array}{l}-0.59 \\
(0.15)\end{array}$ \\
\hline Mean of Price Variable & $\$ 34,280$ & $\$ 31,081$ & $\$ 36,158$ & $\$ 34,806$ & $\$ 30,389$ & $\$ 33,246$ \\
\hline Catholic School Attendance Rate (\%) & 7.1 & 8.5 & 5.6 & 11.2 & 6.9 & 2.8 \\
\hline
\end{tabular}

Each panel is a single regression. All specifications contain block-group fixed effects, subgroup main effects, family structure effects, and the interactions of subgroup effects with family structure effects. Heteroskedasticity-robust standard errors allow for correlation within block groups. 